\title{
Knocking Out Bcsas1 in Botrytis cinerea Impacts Growth, Development, and Secretion of Extracellular Proteins, Which Decreases Virulence
}

\author{
Zhanquan Zhang, Guozheng Qin, Boqiang Li, and Shiping Tian \\ Key Laboratory of Plant Resources, Institute of Botany, the Chinese Academy of Sciences, Beijing 100093, China \\ Submitted 9 May 2013. Accepted 4 February 2014.
}

\begin{abstract}
Pathogenic fungi usually secrete a series of virulence factors to the extracellular environment to facilitate infection. Rab GTPases play a central role in the secretory pathway. To explore the function of Rab/GTPase in filamentous fungi, we knocked out a Rab/GTPase family gene, Bcsas1, in Botrytis cinerea, an aggressive fungal pathogen that infects more than 200 plant species. A detailed analysis was conducted on the virulence and the secretory capability of the mutants. The results indicated that knockout of Bcsas 1 inhibited hyphal development and reduced sporulation of $B$. cinerea on potato dextrose agar plates resulting in reduced virulence on various fruit hosts. Knocking out the Bcsas1 gene led to an accumulation of transport vesicles at the hyphal tip, significantly reduced extracellular protein content, and lowered the activity of polygalacturonase and xylanase in the extracellular medium. However, mutation of Bcsas1 did not affect the expression of genes encoding polygalacturonase and xylanase, suggesting the secretion of these two family enzymes was suppressed in the mutant. Moreover, a comparative analysis of the secretome provided further evidence that the disruption of Bcsas1 in mutant strains significantly depressed the secretion of polysaccharide hydrolases and proteases. The results indicate that Bcsas 1, the Rab8/SEC4-like gene, plays a crucial role in development, protein secretion, and virulence of $B$. cinerea.
\end{abstract}

Botrytis cinerea, a necrotrophic fungal phytopathogen, causes gray mold rot in more than 200 host plant species and is especially destructive on fruits and vegetables, causing serious economic losses (Williamson et al. 2007). B. cinerea can secrete an arsenal of enzymes and metabolites into the extracellular environment during its infection process. Some of them, including oxalic acid (Kim et al. 2008), Nep1-like proteins (Schouten et al. 2008), cerato-platanin family protein (Frías et al. 2011), and xylanase (Noda et al. 2010) have the ability to induce host responses characteristic of a hypersensitive response. In addition, other cell wall-degrading enzymes

Zhanquan Zhang and Guozheng Qin contributed equally to this work.

Corresponding author: Shiping Tian; E-mail: tsp@ibcas.ac.cn; Telephone: +86-10-6283-6559; Fax: +86-10-8259-4675.

* The $\boldsymbol{e}$-Xtra logo stands for "electronic extra" and indicates that four supplementary figures and two supplementary tables are published online and that Figures 2 through 7 appear in color online.

(C) 2014 The American Phytopathological Society secreted by this phytopathogen during early stages of infection, such as endopolygalacturonase (ten Have et al. 1998), pectin methylesterase (Valette-Collet et al. 2003), and xylanase (Brito et al. 2006), have been reported to be necessary for successful establishment and proliferation (lesion extension) in plant tissues. Extracellular proteins also play a role in the molecular dialogue associated with host-pathogen interactions (EsquerréTugayé et al. 2000), suggesting that a precise regulation of these proteins should exist during pathogenesis. Protein secretion by filamentous fungi usually occurs at the hyphal tip or subapical hyphal regions (Conesa et al. 2001). Secretory proteins begin their transport to the extracellular environment by entering the endoplasmic reticulum, in which they are properly folded and modified (Sakaguchi 1997). The proteins are then packed in transport vesicles and transported to the Golgi compartment in which further modifications take place (Novick and Zerial 1997). Finally, the mature proteins are transported to the plasma membrane by secretory vesicles that fuse with the plasma membrane, allowing the secretory proteins to be released to the extracellular environment (Conesa et al. 2001). Many studies on vesicle transport in mammalian cells and yeast have been reported (Chanda et al. 2009; Chen et al. 2001; Van den Hazel et al. 1996; Walworth et al. 1989), but little information is available for filamentous fungi.

As the largest branch of the Ras superfamily, Rab proteins constitute a family of small GTPases that are required for vesicle docking and fusion and, thus, play a central role in the secretory pathway (Novick and Zerial 1997; Punt et al. 2001). Small GTPases function by cycling between active (membraneassociated) and inactive (soluble) GTP-bound states. Some protein effectors are involved in the regulation of Rab activity during this cycling, such as a GDP/GTP exchange factor, which catalyzes GDP/GTP conversion, and GTPase-activating proteins that accelerate GTP hydrolysis. Each GTPase has a specific subcellular localization and takes part in a specific stage of the secretory pathway (Novick and Zerial 1997). Rab family proteins have a number of conservative domains, including four GTP-interaction domains (G1 to G4), five Rab-specific functional domains (F1 to F5), and four subfamily-specific domains (SF1 to SF4) (Pereira-Leal and Seabra 2000; Stenmark and Olkkonen 2001).

Arabidopsis and mammals each have roughly $60 \mathrm{Rab}$ GTPases (Pereira-Leal and Seabra 2001; Rutherford and Moore 2002). The model, unicellular organism Saccharomyces cerevisiae has 11 Rab family proteins, named as YPT or SEC4 (Pereira-Leal and Seabra 2001). The number of Rab proteins ranges from eight to 12 in most of the sequenced fungi (PereiraLeal 2008). Although few genes involved in vesicle secretion in filamentous fungi have been cloned, sequence information from 
these clones can be used to search for homologues that contribute to vesicle secretion in other organisms. In the present work, we isolated and characterized a Rab family gene, $B \operatorname{csas} l$, from B. cinerea. Bcsas1 is a homologue of Rab8 and SEC4. SEC4 was the first Rab protein identified in yeast and was demonstrated to play an important role in both growth and protein secretion (Clément et al. 1998; Mao et al. 1999; Salminen and Novick 1987). There have been reports on two SEC4-like Rab genes ( $\operatorname{srg} A$ and $C L P T 1$ ) from filamentous fungi. In Aspergillus niger, disruption of $\operatorname{srgA}$ led to reduced protein secretion and unusual apical branching but was not essential for growth (Punt et al. 2001). In contrast, disruption of CLPT1 in Colletotrichum lindemuthianum resulted in a lethal phenotype (Dumas et al. 2001). CLPT1 gene function was further studied using a mutant with a dominant-negative allele, and it was ascertained that CLPT1 was necessary for fungal pathogenesis, because it regulated the intracellular transport of secretory vesicles involved in the delivery of proteins to the extracellular medium (Dumas et al. 2001) and the differentiation of infectious structures (Siriputthaiwan et al. 2005). Although the previous reports suggest that the function of SEC4-like genes is conserved in different organisms, some variability has been noted. In order to explore the function of $R a b$ genes in filamentous fungi, we disrupted a Rab/GTPase family gene (Bcsas 1$)$ in $B$. cinerea using homologous recombination and conducted a detailed analysis of the virulence and secretory capability of the resulting mutants. The results indicate that Bcsas 1 plays a crucial role in development, protein secretion, and virulence of $B$. cinerea.

\section{RESULTS}

\section{Bcsas1 encodes a Rab GTPase with homology to Rab8/SEC4.}

A secretion-related Rab/GTPase gene, Bcsasl (BC1G 14039.1), was identified using the $B$. cinerea B05.10 genome database. The Bcsas1 genomic sequence consists of $989 \mathrm{bp}$, and the coding sequence is interrupted by two introns. The deduced Bcsas 1 protein is composed of 203 amino acids with an estimated molecular mass of $22.52 \mathrm{kDa}$ and an isoelectric point (pI) of 7.09. Bcsasl encodes a Rab GTPase with greatest homology to Rab8 and SEC4, both of which have been shown to be involved in post-Golgi transport to the plasma membrane in mammalians and yeasts (Chen et al. 2001; Goud et al. 1988; Huber et al. 1993; Peranen et al. 1996; Walworth et al. 1989). Alignment of amino acid sequences showed the sequence of Bcsas1 protein with the specific hits of Rab8/SEC4 and $54.19 \%$ identity with SEC4 protein of $S$. cerevisiae, $58.37 \%$ with Rab8 protein of Drosophila melanogaster, and $60.59 \%$ with Rab8 protein of Mus musculus (Supplementary Fig. S1). Phylogenetic tree analysis also showed that Bcsas1 protein has significant similarity to SEC4 protein of S. cerevisiae (Supplementary Fig. S4).

\section{The expression of Bcsas 1 was induced by oxidative stress.}

Rapid accumulation of reactive oxygen species, referred to as an oxidative burst, often occurs in the host at the site of pathogen invasion and is considered an early defense reaction (Segal 2005; Temme and Tudzynski 2009). Preliminary experiments indicated that exogenous application of $5.0 \mathrm{mM} \mathrm{H}_{2} \mathrm{O}_{2}$ could inhibit germination of conidia by $80 \%$, and at $10 \mathrm{mM}$, germination was inhibited completely (Supplementary Fig. S2). Quantitative real-time polymerase chain reaction (PCR) was carried out to determine if oxidative stress could affect the expression pattern of Bcsasl in B. cinerea. The conidia were incubated in potato dextrose broth (PDB) till germinated $(8 \mathrm{~h})$, and then, $\mathrm{H}_{2} \mathrm{O}_{2}$ was added before further incubation for $1 \mathrm{~h}$. The result indicated that the expression of Bcsasl was significantly upregulated under $\mathrm{H}_{2} \mathrm{O}_{2}$ stress (Fig. 1). The average relative transcript abundance of $B$ csas 1 was $118 \%$ higher than the control in response to $10 \mathrm{mM} \mathrm{H}_{2} \mathrm{O}_{2}$ (Fig. 1). There are $10 \mathrm{Rab}$ family genes in $B$. cinerea. The results showed that all these genes were upregulated upon exposure to $\mathrm{H}_{2} \mathrm{O}_{2}$ stress (Fig. 1),
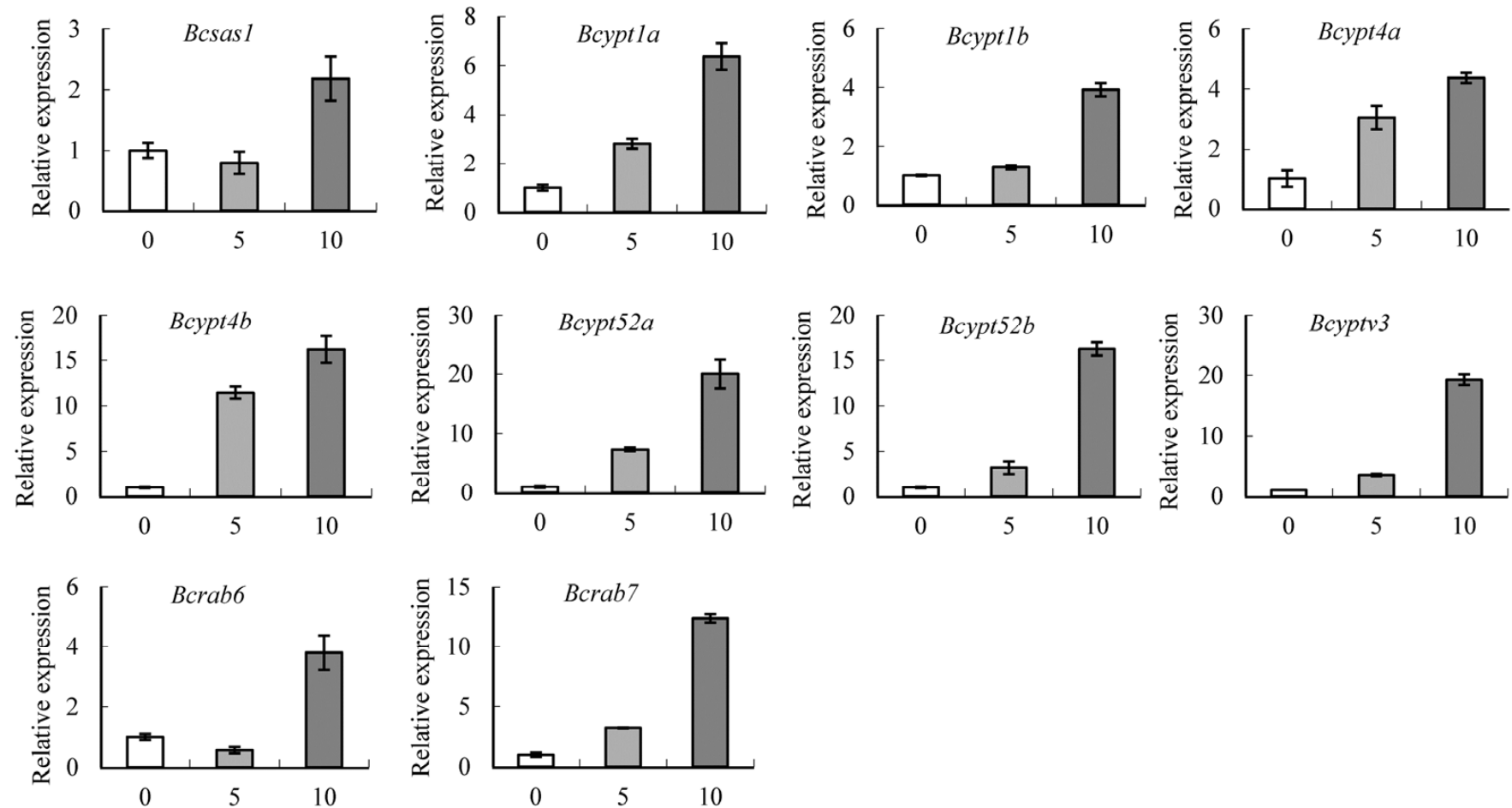

Fig. 1. Expression patterns of Rab family genes in Botrytis cinerea under oxidative stress. The conidia of the wild-type B05.10 were incubated in potato dextrose broth for $8 \mathrm{~h}$, and the RNA was extracted after 1-h treatment with $\mathrm{H}_{2} \mathrm{O}_{2}$. Bcactin (BC1G_08198.1) and Bctubulin (BC1G_00122.1) were used as loading controls. Bars indicate standard deviation of means of three replications. 
suggesting that Rab family genes in $B$. cinerea could respond to oxidative stress.

\section{The generation of Bcsas1 deletion mutants.}

Bcsas 1 deletion mutants were obtained using a gene replacement strategy (Fig. 2A). A part of the gene sequence (158 bp) was replaced with a hygromycin-resistance cassette. The deduced amino acids coded by the deleted DNA sequence contains five conserved domains, including a putative GDI interaction site, putative effector interaction site, Rab family motif 4, Rab family motif 5 , and switch II region. A total of 40 independent hygromycin-resistant colonies were obtained from one transformation experiment. Flank-spanning PCR was used to verify the insertion in the colonies, using SJ-F forward and SJ-R reverse primers, which are located outside the $\mathrm{L}$ flank and inside the hygromycin-resistance cassette, respectively (Fig. 2A). A 2.4-kb fragment was amplified only from the transformants, which indicated the correct integration. Three of the hygromycinresistant colonies, $\Delta b s 3, \Delta b s 5$, and $\Delta b s 8$, showed the diagnostic fragment (Fig. 2B). To exclude heterokaryons, one round of single-spore isolation was carried out. Three homokaryotic Bcsas 1 deletion mutants, named as $\Delta b s 3-3, \Delta b s 5-11$, and $\Delta b s 8-13$, were obtained. The PCR assay of an internal fragment showed that Bcsas1 was completely removed from the mutants (Fig. 2C). The three mutants were subjected to Southern blot analysis, using the labeled $\mathrm{L}$ fragment as a probe to ensure that there was no ectopic integration. The wild-type strain B05.10 showed a 2.6-kb hybridizing band and the three mutants had a $5.0-\mathrm{kb}$ band, as expected (Fig. 2D). These results indicated that the three mutants had a single copy insertion of Bcsas1.

\section{Bcsas1 mutants exhibit reduced radial growth, sclerotia formation, and sporulation.}

Dramatic changes in vegetative growth were observed in the Bcsas 1 mutants. Radial growth was evaluated as colony diameter on potato dextrose agar (PDA) plates. The growth rate of mutants was drastically reduced compared with wild-type strain B05.10 (Fig. 3A and C). On the fourth day after inoculation, the colony diameter of the wild type strain was as large as the plate $(90 \mathrm{~mm})$. In contrast, the diameter of the mutant strains was only about $10 \mathrm{~mm}$ on average (Fig. 3A). Mycelia of mutants were thinner, with more branches as compared with the wild-type strain. Hyphal tips of the mutants frequently appeared swollen (Fig. 3B, arrows). The three Bcsas 1 mutants did not develop sclerotia as was observed in the wild-type B05.10 (Fig. 3A). The mutant $\Delta b s 3-3$ and wild-type strain were cultured on PDA plates amended with different concentrations of hydrogen peroxide in order to determine the effect of the Bcsasl deletion on growth of B. cinerea under oxidative stress. The mutant showed a slight reduction in growth compared with wild type, implying that the mutant is less sensitive to oxidative stress than wild type (Fig. 3D). The quantity of

A
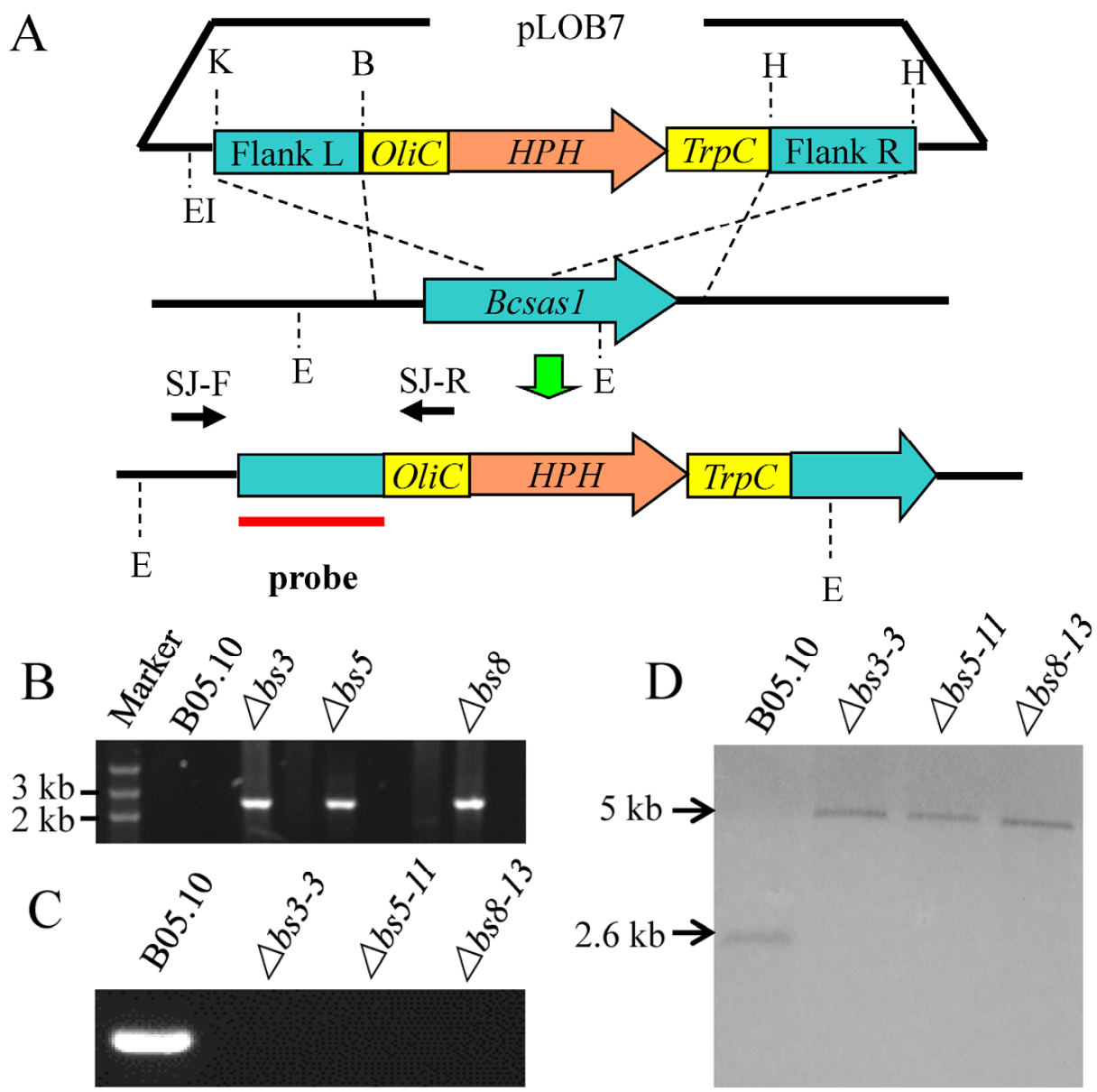

Fig. 2. Generation of Bcsas1 mutants. A, Replacement strategy for deletion of Bcsas1. Flank L and Flank R were amplified by primer pairs BSL-F and BSL$\mathrm{R}$ and BSR-F and BSR-R, respectively. The replacement vector $\mathrm{p} \triangle \mathrm{BS}$ was constructed by cloning Flank $\mathrm{L}$ and Flank R on each side of the hygromycinresistance cassette of pLOB7. B, Detection of the mutants by flank-spanning polymerase chain reaction (PCR). A 2.4-kb fragment amplified with primer pair SJ-F and SJ-R from the transformants deriving from homologous integration. C, PCR assay of the internal fragment of Bcsas 1 in wild type and mutants. D, Southern blot analysis of B05.10 (WT) and three mutants, $\Delta b s 3-3, \Delta b s 5-11$, and $\Delta b s 8-13$. The genomic DNA was digested with EcoRV, separated in agarose gel, blotted, and hybridized with probe (Flank L labeled with digoxigenin). Primer binding sites are indicated by arrows and probe is indicated by black beeline. K, KpnI; B, BamHI; H, HindIII; EI, EcoRI; and E, EcoRV. 
conidia was assessed 7 days postinoculation. Production of conidia in the wild-type strain was more than 100-fold higher than in the mutant strains (Fig. 4A and B). In sharp contrast, the rate of germination and mycelial growth in the wild type and mutants did not differ when they were grown in liquid culture. After $8 \mathrm{~h}$ of incubation, almost all the conidia had germinated (Fig. 4C). The dry weight of mycelium did not show a significant difference between wild type and mutants after culturing for 3 days in Czapeck liquid medium (Fig. 4D). Complementation of the mutant $\Delta b s 3-3$ with the Bcsas 1 gene under control of its own promoter and terminator restored wild-type growth and colony morphology (Figs. 3 and 4).

\section{Bcsas1 mutants exhibit less virulence on host plants.}

To determine the virulence of the mutants on host plant tissue, we first monitored the penetration process on onion epidermis and found that the Bcsas 1 mutants could successfully penetrate the epidermis and develop in epidermal cells (Supplementary Fig. S3). Tomato and apple fruit as well as tomato leaves were then selected as hosts to further test the virulence of Bcsas I mutants. On tomato fruit, lesion expansion rates of the three mutants were significantly lower than that of wild-type strain B05.10. In contrast to the mutants, the B05.10 strain also developed more mycelia and sporulated abundantly at the wound site (Fig. 5A and D). On apple fruit, the virulence of Bcsas 1 mutants was sharply depressed. After 4 days, slight lesions were detected in the mutant-inoculated apple fruit, whereas lesion size in B05.10-inoculated fruit was $30 \mathrm{~mm}$ (Fig. 5B and E). However, mutant strains could not penetrate the epidermis of detached tomato leaves (Fig. 5C and F). Complementation of the mutant strain, however, could restore its virulence, making it similar to the wild-type strain. The results demonstrated that the virulence of the Bcsasl mutants was significantly impaired on different plant hosts.

\section{Disruption of Bcsas1 blocks protein secretion.}

To determine if the disruption of Bcsasl affects exocytosis, mycelia of B05.10 and the Bcsas 1 mutant $\Delta b s 3-3$ were stained with FM4-64, an amphiphilic styryl dye that can insert itself into the outer leaflet of the plasma membrane. This dye has been widely used as a fluorescent reporter of components of the vesicle trafficking network (Fischer-Parton et al. 2000; Vida and Emr 1995). A stronger fluorescent signal, indicating the accumulation of trafficking vesicles, was detected at the hyphal tips of the mutant strains, compared with B05.10 (Fig. $6 \mathrm{~A})$. In order to analyze the polysaccharide in the cell walls of the wild-type strain and mutant, Calcofluor white staining was performed. The result showed that the distribution of polysaccharides had stronger polarity at the tip part of the wild-type strain, compared with the mutant (Fig. 6B). This implied that cell-wall synthesis is more active at the hyphal tip of the wild type than that of the mutant. To test the possibility that Bcsasl
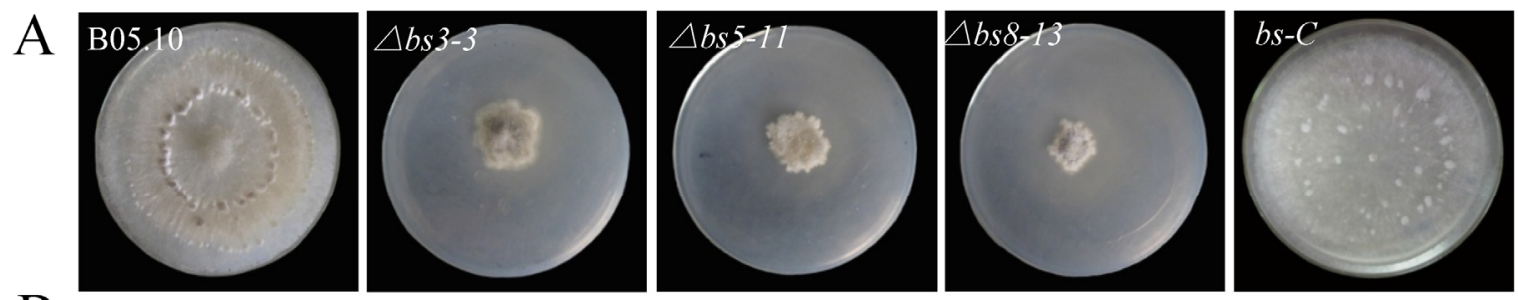

$\mathrm{B}$
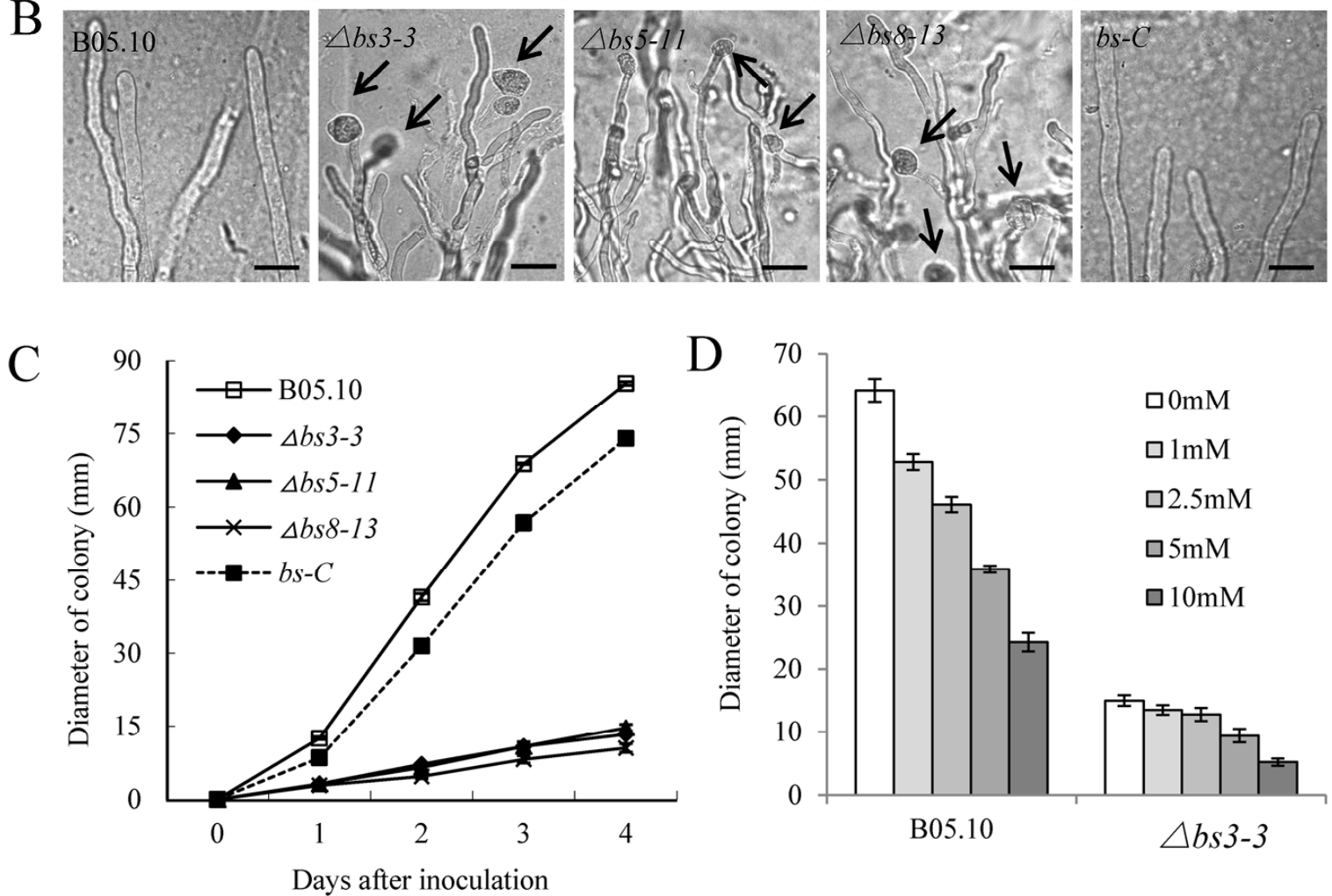

Fig. 3. Radial growth and mycelial morphology of the wild type and mutants on potato dextrose agar (PDA) plates. A, Colony phenotype of B05.10, the mutants, and the complemented strain after growing for 7 days on PDA plates. B, Morphology of 3-day-old hyphae growing on PDA plates. The scale bars represent $20 \mu \mathrm{m}$. C, Radial growth rate on PDA plates. Bars indicate standard deviation of means of three replications. D, Colony diameters of mutant $\Delta b s 3-3$ and $\mathrm{B} 05.10$ after 3 days growth under $\mathrm{H}_{2} \mathrm{O}_{2}$ stress. 
A
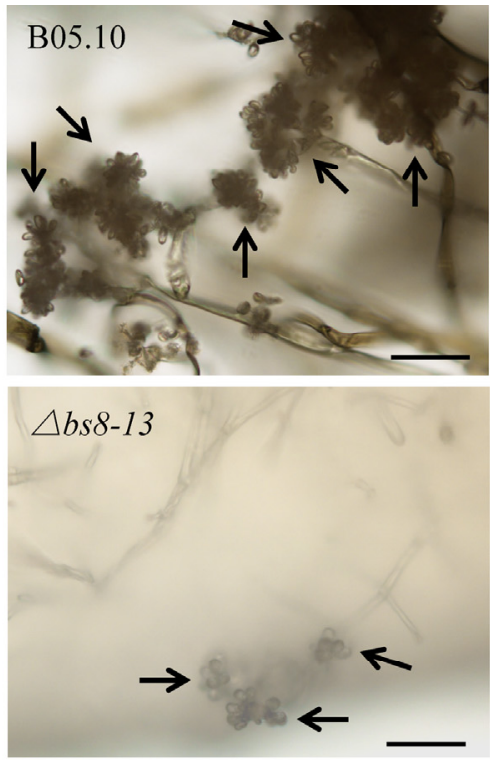

$\mathrm{B}$

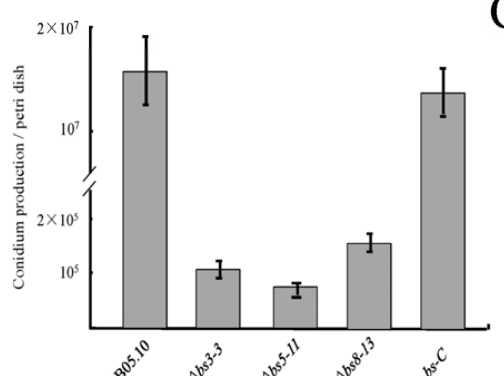

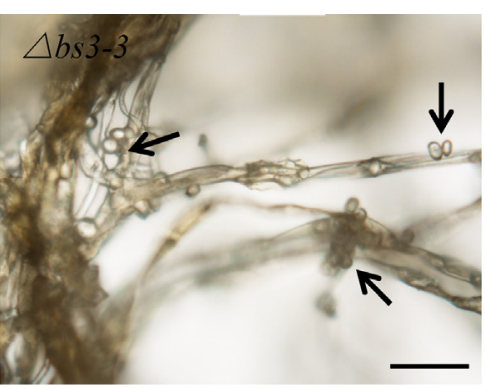
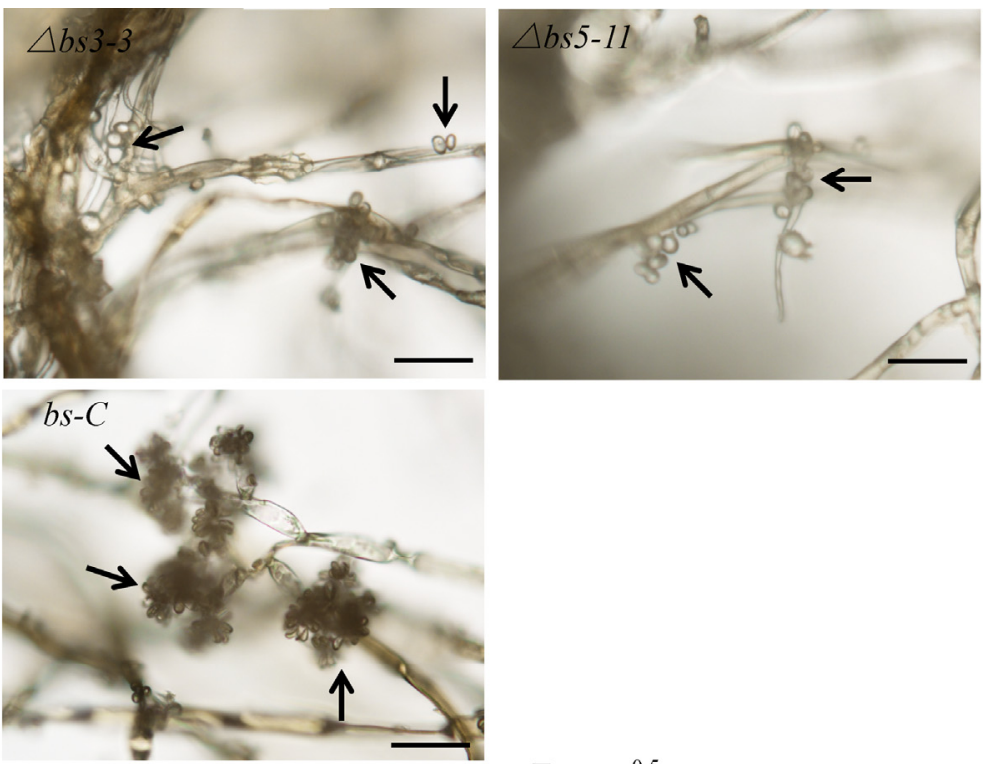

$\mathrm{C}$

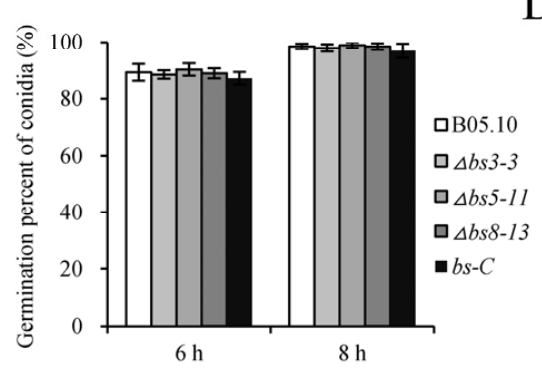

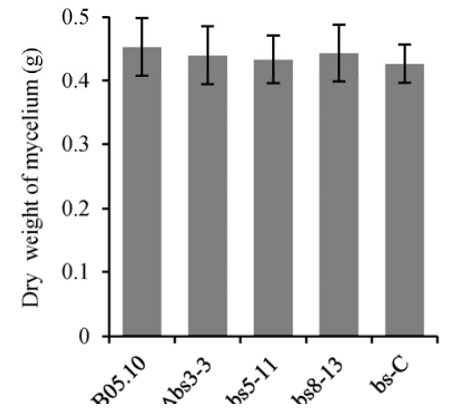

Fig. 4. The sporulation, conidia germination, and mycelial dry weight assays. A, Sporulation examination of wild type, mutants, and the complemented strain, incubated for 7 days, under microscope. Arrows indicate the conidia. Scale bars represent $50 \mu \mathrm{m}$. B, Conidium production of wild type, mutants, and the complemented strain, incubated for 7 days. C, Germination rate examination of wild type, mutants, and the complemented strain in potato dextrose broth. D, The dry weight of mycelium assay. A suspension of $5 \times 10^{6}$ conidia was inoculated into $100 \mathrm{ml}$ Czapeck liquid medium and was cultured for 3 days.
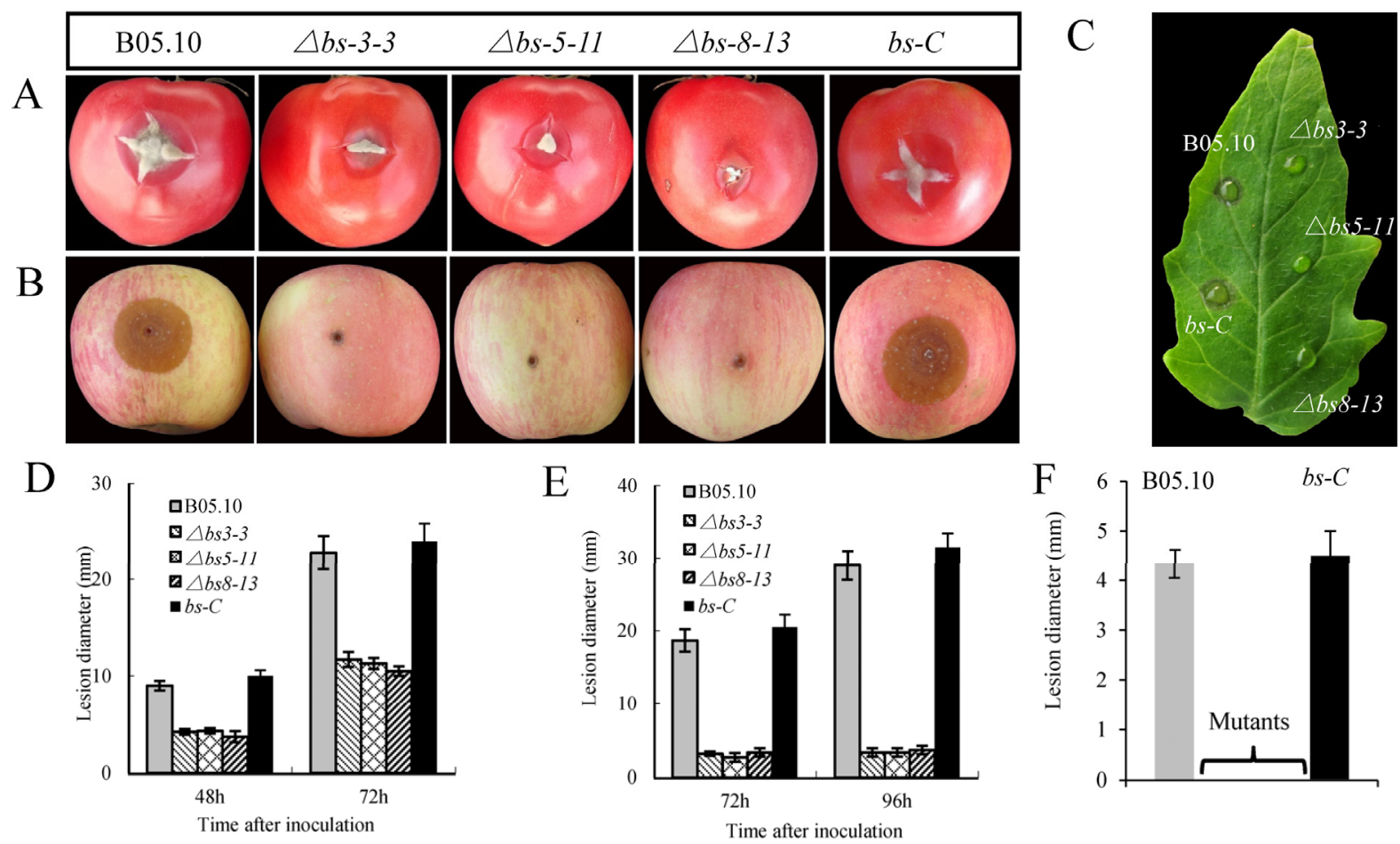

Fig. 5. A, Virulence assays on tomato fruit, 3 days after inoculation, B, apple fruit, 4 days after inoculation, and $\mathbf{C}$, on detached tomato leaves, 2 days after inoculation. D, Statistical analysis of the lesions on tomato fruits, $\mathbf{E}$, on apple fruits, and $\mathbf{F}$, on detached tomato leaves. The tomato and apple fruits were wounded with a sterile nail, and the leaves were wounded slightly with a hairbrush before inoculation. 
regulates protein secretion, proteins were extracted from the supernatant of cultures growing in Czapeck liquid medium for 3 days. Proteins were separated by one-dimensional sodium dodecyl sulfate-polyacrylamide gel electrophoresis (SDSPAGE). Results indicated that the quantity of extracellular protein in the supernatant obtained from mutant cultures was significantly lower than in supernatant extracts obtained from wild-type cultures (Fig. 6B). The disruption of the Bcsas1 gene also led to a dramatic reduction in polygalacturonase and xylanase activity (Fig. 6C), both of which are crucial pathogenic factors secreted by $B$. cinerea (Brito et al. 2006; ten Have et al. 1998). In contrast, there was no significant difference, at the transcription level, of the polygalacturonase and xylanase genes between wild type and mutants (Fig. 6E). The results indicated that the secretion of these two family extracellular hydrolytic enzymes was suppressed in mutant.

\section{Analysis of the secretome.}

Comparative analysis of the wild-type B05.10 and Bcsas1deletion mutant secretome was performed. To obtain sufficient extracellular proteins, strains were cultured in Czapeck liquid medium for $120 \mathrm{~h}$, and proteins were extracted from the supernatant and were subjected to two-dimensional (2-D) electrophoresis. First-dimension separation utilized immobilized $\mathrm{pH}$ gradient strips spanning a $\mathrm{pH}$ range of 4 to 7 . More than 400 protein spots were detected in each gel, using Image Master 2D Elite software (Fig. 7A). Spots that showed statistically significant changes $(P<0.05)$ of more than 1.5 -fold in relative abundance were designated as differential spots. A total of 33 differentially expressed proteins were detected in the secretome of Bcsas 1 deletion mutant, including 24 downregulated and nine upregulated proteins. Ignoring very faint spots and spots with undefined shapes and areas, the remaining 24 spots were analyzed by tandem mass spectrometry (MS/MS). Using the NCBInr database, 19 of the 24 spots were identified with MOWSE scores significantly higher than the threshold $(P<$ $0.05)$. These included 14 downregulated proteins and five upregulated proteins (Fig. 7B). Protein spots D8 and D9 (alphaL-arabinofuranosidase) and spots U1, U2, and U3 (immunoglobulin E-binding protein) were identified as the same protein. Their location in the gels (as defined by their $\mathrm{pI}$ and molecular mass) differed slightly, perhaps due to different posttranslational modifications of the same protein. The group of downregulated proteins was composed of nine polysaccharide hydrolases, four proteases, and one lipase (Fig. 7C). The putative subcellular localization of the identified proteins was identified using the SignalP algorithm with ProtComp 9.0. Most of the identified proteins have designations of extracellular localization, except N2 (cytoplasm) and U9 (mitochondria) (Supplementary Table S2). The appearance of N2 (glutamate carboxypeptidase) and U9 (mannitol dehydrogenase) in the secretome may have been the result of cell lysis or secretion through a nonclassical secretory pathway.

\section{DISCUSSION}

Various mechanisms exist that allow plant hosts and microbes to establish a "molecular dialogue" that directly impacts virulence and pathogenicity (Esquerré-Tugayé et al. 2000). Pathogenic fungi often secrete a series of virulence factors into the extracellular environment that facilitate infection and allow the pathogen to assimilate essential nutrients from the host (Conesa
A

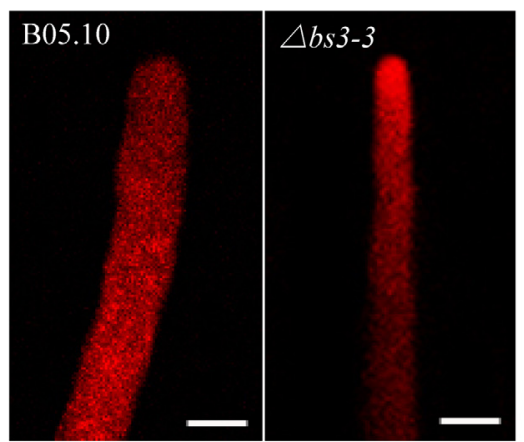

$\mathrm{D}$

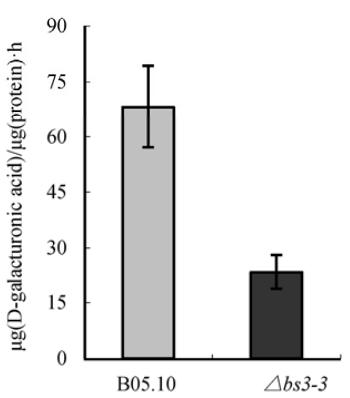

Polygalacturonase
B
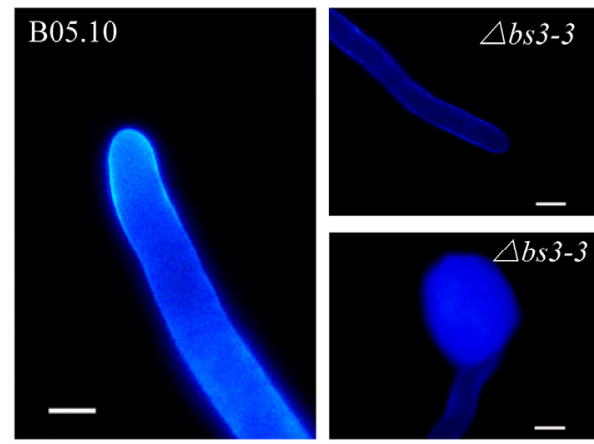

E
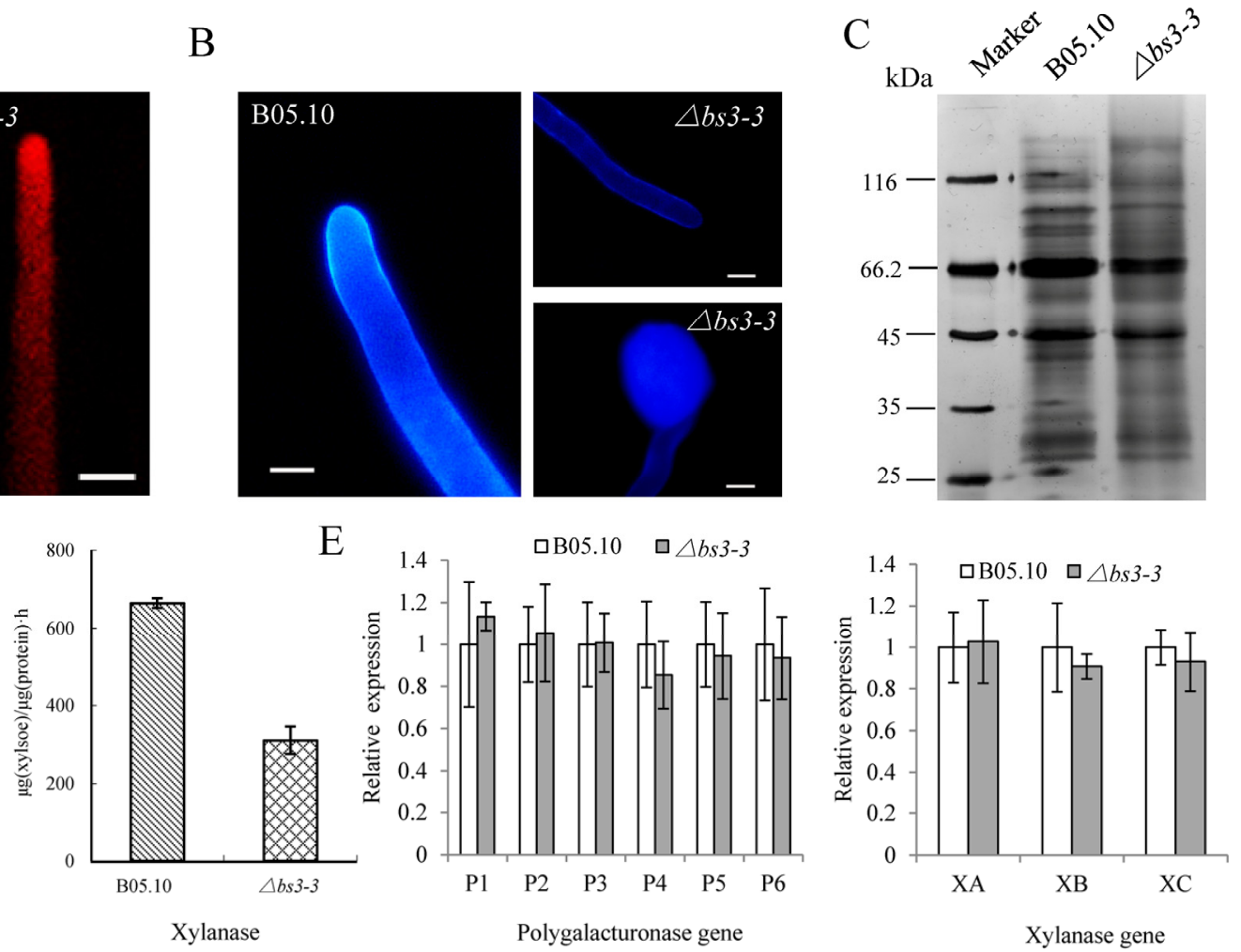

Fig. 6. Determination of secretion ability. A, Confocal image of growing hyphal tip of wild-type B05.10 and mutant $\Delta b s 3-3$ stained with $5 \mu M$ FM4-64. The scale bars represent $10 \mu \mathrm{m}$. B, Calcofluor white staining at hyphal tip of B05.10 and $\Delta b s 3-3$. C, Secreted proteins separated by $12 \%$ Tris-glycine sodium dodecyl sulfate polyacrylamide gel electrophoresis (SDS-PAGE) and silver stained. The loaded proteins were extracted from the same fungal biomass determined as dry weight. D, The activities of cell wall-degrading enzymes in the culture supernatants of wild-type B05.10 and mutant $\Delta b s 3-3$ incubated for 3 days. Bars indicate standard deviation of means of three replications. E, Expression assays of polygalacturonase genes and xylanase genes in wild-type B05.10 and $\Delta b s 3$-3 incubated for 3 days. Gene ID: P1, BC1G_00240.1; P2, BC1G_13367.1; P3, BC1G_04246.1; P4, BC1G_02003.1; P5, BC1G_00230.1; P6, BC1G_08033.1; XA, BC1G_00576.1; XB, BC1G_03590.1; and XC, BC1G_01778.1. Bars indicate standard deviation of means of three replications. 
et al. 2001; Espino et al. 2010). Extracellular secretion is dependent on vesicle transport and Rab GTPases are well-established regulators of this process (Novick and Zerial 1997). Rab GTPases have been shown to influence major steps in vesicle transport, such as vesicle budding, delivery, tethering, and fusion of the vesicle membrane with the target compartment (Grosshans et al. 2006). Based on a genomic analysis of $B$. cinerea, we identified 10 Rab family genes (Table 1). Expression of the 10 Rab genes was upregulated in response to exogenous oxidative stress (Fig. 1), suggesting that they are involved in plant-microbe interactions.

The homologues of Bcsas1, Rab8 and SEC4, have been extensively studied in model organisms (Huber et al. 1993; Peranen et al. 1996) and have been reported to be involved in post-Golgi transport of vesicles to the plasma membrane (Nielsen et al. 2008). Rab8 in mammalian cells and SEC4 in yeast are essential to several life processes (Goud et al. 1988; Hattula et al. 2006; Salminen and Novick 1987). Rab8-deficient mice exhibit a marked reduction in the absorption rate of nutrients in the small intestine, which eventually leads to death (Sato et al. 2007). In S. cerevisiae, SEC4 null mutants are nonviable (Mao et al. 1999). The dominant-negative mutations generated by substituting different amino acids coded by the SEC4 gene inhibited growth and protein secretion (Walworth et al. 1989). In contrast to SEC4, disruption of Bcsas 1 in B. cinerea was not lethal but had a striking effect on hyphal growth and morphology on solid medium (Fig. 3). The mutants were characterized by smaller, compact colonies as well as reduced sporulation on PDA (Fig. 4). Punt and associates (2001) re- ported that disruption of $\operatorname{srgA}$, a homologue of SEC4, in Aspergillus niger, also led to a slower growth rate. They suggested the effect on hyphal growth was due to the disruption of the proper targeting of secretory vesicles containing cell-wall synthases and hydrolases to the plasma membrane (Punt et al. 2001). The expression of Bcsasl was induced under $\mathrm{H}_{2} \mathrm{O}_{2}$ stress, suggesting that this gene plays an important role in response to $\mathrm{H}_{2} \mathrm{O}_{2}$ stress. Interestingly, we found that Bcsas 1 mutants were less sensitive to oxidative stress compared with wild type (Fig. 3D). This implies that Bcsas 1 might negatively influence the response of $B$. cinerea to $\mathrm{H}_{2} \mathrm{O}_{2}$ stress. To better understand the function of Bcsas 1 , we stained hyphal tips of $B$. cinerea with FM4-64 and found the highest level of fluorescence at the hyphal tips of mutant strains, indicating that vesi-

Table 1. The Rab family genes of Botrytis cinerea according to alignment of the protein sequence at the National Center for Biotechnology Information database

\begin{tabular}{lll}
\hline Gene name & \multicolumn{1}{c}{ Gene ID } & Orthologous gene \\
\hline Bcsas1 & BC1G_14039.1 & Rab8, Sec4 \\
Bcypt1a & BC1G_02688.1 & Ypt1, Rab1 \\
Bcypt1b & BC1G_09346.1 & Rab11 \\
Bcyptv3 & BC1G_06093.1 & Rab18 \\
Bcrab6 & BC1G_08710.1 & Rab6 \\
Bcrab7 & BC1G_07591.1 & Rab7 \\
Bcypt52a & BC1G_05919.1 & Ypt52, Rab5, Rab22 \\
Bcypt52b & BC1G_07328.1 & Ypt52, Rab5, Rab22 \\
Bcypt $4 a$ & BC1G_01676.1 & Rab4 \\
Bcypt $4 b$ & BC1G_12412.1 & Rab2 \\
\hline
\end{tabular}

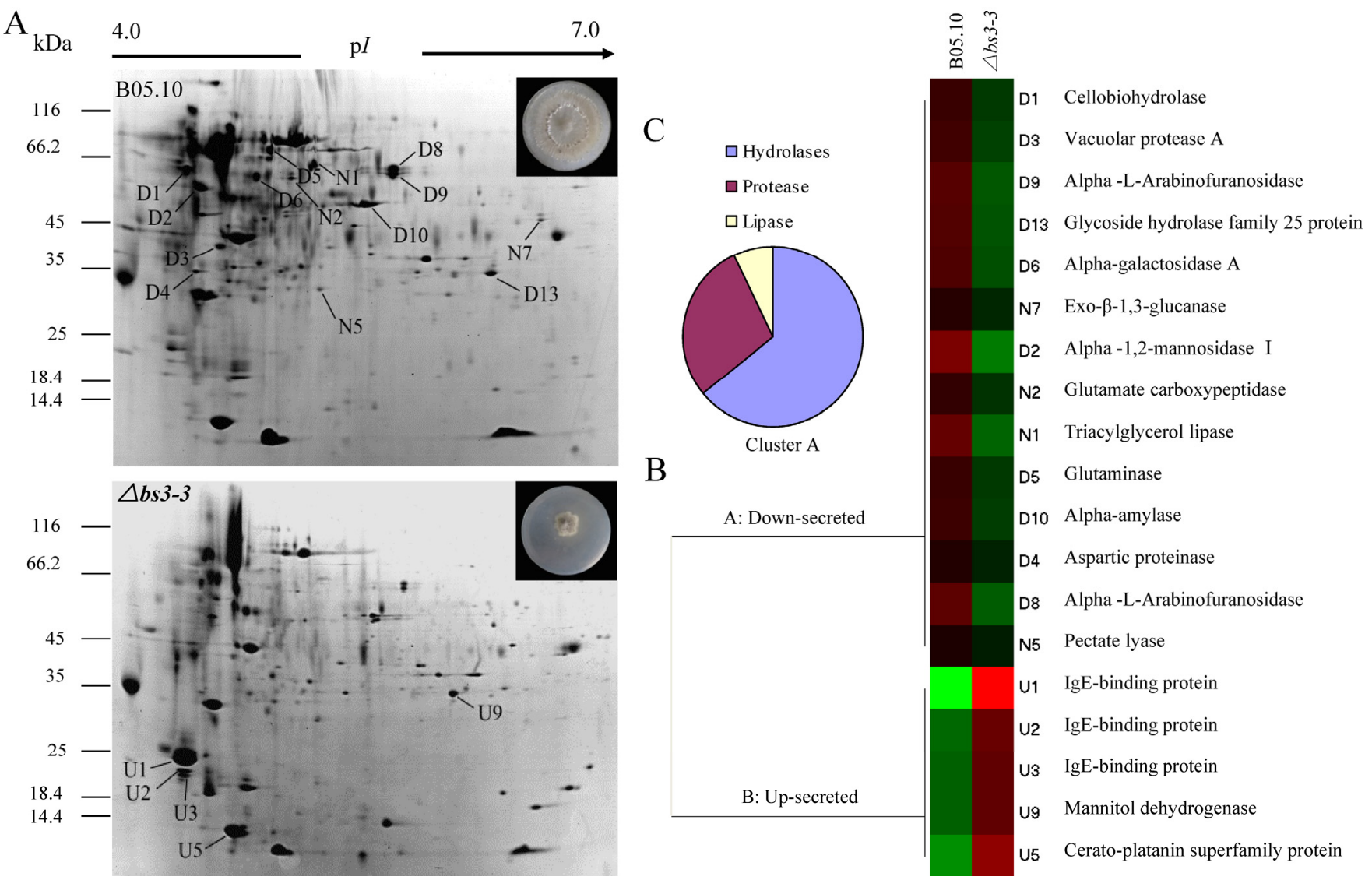

Fig. 7. Two-dimensional (2-D) sodium dodecyl sulfate-polyacrylamide gel electrophoresis analysis of secretome. A, 2-D electrophoresis patterns of secretome from wild type and mutant $\Delta b s 3-3$ cultured for 5 days in Czapeck liquid medium. Arrows indicate the proteins identified by tandem mass spectrometry that differed in abundance by more than 1.5-fold between the wild type and mutant. B, Clustering analysis of the changes in protein secretion. Spots identified were clustered into two clusters (I and II) according to their percentage of volume, using the Pearson clustering algorithm. A bright red color indicates a high protein secretion value and a bright green color represents a low protein secretion value. C, Functional classification of downregulated proteins in cluster I. 
cles were fusing with the plasma membrane (Fig. 6A). Further analysis showed that the extracellular activity of polygalacturonases and xylanases was significantly reduced in the mutant, but the transcription levels of the genes encoding these two hydrolases were not affected (Fig. 6D and E). These data suggest that the vesicle transport was blocked in the mutant. The results of Calcofluor white staining implied that the transport of polysaccharides, which were used for cell-wall synthesis, was impaired, resulting in the accumulation of polysaccharides at apical or subapical hyphal regions. This may partially explain the formation of swollen structures in mutants. The data indicate that Bcsas 1 can functionally regulate hyphal growth and sporulation by affecting extracellular secretion of proteins. CLPT1, a putative SEC4 homologue in the filamentous fungus Colletotrichum lindemuthianum, was shown to be nonessential for hyphal elongation (Siriputthaiwan et al. 2005). Thus it appears that SEC4 homologues may have different functions in different organisms.

We also found that Bcsasl disruption mutants exhibited different levels of virulence on different plant hosts. The pathogenicity of Bcsas 1 mutants was significantly impaired on tomato and apple fruit but completely lost on tomato leaves (Fig. 5). The reduced virulence in the Bcsasl mutants, compared with the wild type, may have been due to the lower growth rate (Fig. 3A and B) and reduced activity of cell walldegrading enzymes as well as less protein secretion in general (Fig. 6). Polygalacturonase and xylanase have been shown to be required for virulence in $B$. cinerea (Brito et al. 2006; ten Have et al. 1998). In the current study, one-dimensional SDSPAGE of extracellular protein extracts indicated that protein secretion was strongly impaired in the Bcsasl mutants (Fig. 6C). A comparative analysis of the secretome of the wild type and the Bcsas 1 deletion mutants provided further evidence that mutation of Bcsasl significantly depressed the secretion of polysaccharide hydrolases and proteases (Fig. 7). This finding is important for understanding the function of Bcsasl in regulating protein secretion in $B$. cinerea. Plant cell walls are mainly composed of polysaccharides such as pectin, cellulose, and hemicelluloses (Jamet et al. 2006). Among the nine polysaccharide hydrolases identified in our study, cellobiohydrolase (D1, BC1G_10880.1), $\alpha$-galactosidase (D6, BC1G_00111.1), $\alpha$-L-arabinofuranosidase (D8 and D9, BC1G_04994.1), and pectate lyase (BofuT4_P035890.1) have been reported to play an important role in cell-wall metabolism (English and Albersheim 1969; ten Have et al. 1998; Vu et al. 2012; Yajima et al. 2009). $\beta$-1,3-exoglucanase, a polysaccharide hydrolase downregulated in the secretome, has been reported to be involved in fungal morphogenesis by remodeling the $\beta$-1,3-glucan network of fungal cell wall or utilizing the extracellular $\beta$-1,3-glucan (Stubbs et al. 1999; Tamano et al. 2007). Although the secretion of one $\beta$-1,3-exoglucanase is obviously reduced in the mutants, the results of an agar plate assay indicated that the ability of the mutants to catabolize extracellular $\beta$-1,3-glucans was not significantly altered (data not shown). The function of this $\beta$-1,3-exoglucanase may be complemented by other members of this gene family.

Proteases are another group of enzymes that participate in the molecular dialogue between plants and pathogens (Espino et al. 2010). We found a greater level of secreted proteases and, in some cases, differential expression in the wild type compared with the Bcsas 1 mutant (Fig. 7). One of the identified proteases, a vacuolar protease A (D5, BC1G_06849.1), has been reported to be involved in spore morphogenesis and adaptation to nutritional stress in S. cerevisiae (Van den Hazel et al. 1996). In Aspergillus fumigatus, a vacuolar protease, ALP2, is involved in conidiogenesis (Reichard et al. 2000). Proteases have also been shown to play an important role dur- ing the infection process. Fungal proteases could potentially contribute to plant cell-wall softening by degrading proteins, such as extensions, in the cell wall (Jamet et al. 2006). Proteases also contribute to the degradation of defense proteins secreted by host plants, thus facilitating infection. Furthermore, the amino acids released by the action of the proteases can be used to support fungal growth. Aspartic proteinase plays a crucial role in the pathogenesis of the fungal pathogen Candida albicans (Naglik et al. 2003). This protease was also identified as being differentially expressed in the Bcsas 1 mutant (Fig. 7). However, ten Have and associates (2010) reported that virulence was not affected in a mutant of $B$. cinerea containing a knockout of the aspartic proteinase gene Bcap8. Li and associates (2012) suggested that the loss of Bcap8 activity in the knockout mutants may be partially compensated by expression of other Bcap family members.

In summary, the data suggest that Bcsasl, a Rab8- and SEC4-like gene in B. cinerea, plays an important role in hyphal growth and protein secretion by regulating vesicle transport. The mutation of Bcsasl greatly impaired protein secretion, thus resulting in lower levels of enzyme activity (hydrolases and proteases) in the extracellular medium. The reduction of growth rate and extracellular secretion resulted in decreased virulence of $B$. cinerea. Collectively, the data indicate that Bcsas 1 in $B$. cinerea is required for hyphal development and virulence. Future work will focus on the role of all ten Rab family genes in the regulation of virulence in $B$. cinerea.

\section{MATERIALS AND METHODS}

\section{Fungal strains and culture conditions.}

The $B$. cinerea haploid strain B05.10 was supplied by P. Tudzynski (Westfaelische Wilhelms-Universitaet Muenster, Germany) and was used as the wild-type strain. All strains were regularly incubated on PDA plates at $22^{\circ} \mathrm{C}$. PDB and Czapeck liquid medium (per liter: $2.5 \mathrm{~g}$ of $\mathrm{NaNO}_{3}, 0.5 \mathrm{~g}$ of $\mathrm{KCl}, 0.5 \mathrm{~g}$ of $\mathrm{MgSO}_{4} \cdot 7 \mathrm{H}_{2} \mathrm{O}, 10 \mathrm{mg}$ of $\mathrm{FeSO}_{4} \cdot 7 \mathrm{H}_{2} \mathrm{O}, 1 \mathrm{~g}$ of $\mathrm{K}_{2} \mathrm{HPO}_{4}, 10 \mathrm{~g}$ of apple pectin) were used as liquid medium for collection of mycelia and extracellular proteins. SH agar medium containing 0.6 M sucrose, $5 \mathrm{mM}$ HEPES, $1 \mathrm{mM}\left(\mathrm{NH}_{4}\right)_{2} \mathrm{HPO}_{4}$, and $1 \%$ agar was used to regenerate $B$. cinerea protoplasts. MEA plates (1\% malt extract and $1.5 \%$ agar) were used for further selecting transformants.

\section{Construction of the Bcsas1 replacement vector and transformation.}

For construction of the Bcsas1 replacement vector, flank L, containing the 395-bp upstream sequence of the Bcsasl gene and the 428-bp Bcsasl gene sequence, was amplified by PCR with primer pair BSL-F and BSL-R from genomic DNA of $B$. cinerea $\mathrm{B} 05.10$; the KpnI and BamHI sites were added at the end of the primers, respectively (Supplementary Table S1). Flank R containing the 420-bp Bcsas 1 gene sequence and the 458-bp downstream sequence was amplified by PCR with primer pair BSR-F and BSR-R from genomic DNA; a HindIII site was added at both ends of this primer pairs. Plasmid pLOB7, provided by J. van Kan (Wageningen Agricultural University, The Netherlands), was used in the disruption of Bcsas1. It carries the hygromycin phosphotransferase gene hph under control of the A. nidulans oliC promoter and trpC terminator and confers resistance to hygromycin. Fragment $\mathrm{L}$ was digested by KpnI and BamHI and fragment R by HindIII and they were cloned into the corresponding site of the vector $\mathrm{pLOB} 7$, resulting in vector $\mathrm{p} \Delta \mathrm{BS}$. Before transformation, the vector $\mathrm{p} \Delta \mathrm{BS}$ was linearized with EcoRI.

Conidia from sporulating cultures were collected and inoculated in PDB $\left(10^{5}\right.$ conidia $\left.\mathrm{ml}^{-1}\right)$. Then the cultures were incu- 
bated in a rotary shaker at $22^{\circ} \mathrm{C}$ and $160 \mathrm{rpm}$ (HZQ-F100; HDL, Harbin, China) for $24 \mathrm{~h}$. Mycelium was collected by filtration and was washed once with sterile water and twice with $\mathrm{KC}$ buffer $\left(0.6 \mathrm{M} \mathrm{KCl}, 50 \mathrm{mM} \mathrm{CaCl}_{2}\right)$. The mycelium was suspended in $20 \mathrm{ml}$ of $0.5 \%$ Glucanex (Sigma, St. Louis) solution (dissolved by $\mathrm{KC}$ buffer) and was incubated at $25^{\circ} \mathrm{C}$ and 100 rpm (HZQ-F100) for $2 \mathrm{~h}$ to generate protoplasts. The digested suspension was filtered by nylon membrane with $25 \mu \mathrm{m}$ mesh size. Protoplasts were pelleted by centrifugation at $1,200 \times g$ for $10 \mathrm{~min}$, were washed twice, and were resuspended in $\mathrm{KC}$ buffer to a final concentration of $10^{8}$ protoplasts per milliliter. Protocols for transformation were slightly modified from an established procedure (Hamada et al. 1994). A suspension of $200 \mu \mathrm{l}$ containing $2 \times 10^{7}$ protoplasts was maintained on ice for $5 \mathrm{~min}$, and subsequently, $100 \mu \mathrm{g}$ of transformation vector dissolved in $100 \mu \mathrm{l}$ of $\mathrm{KC}$ buffer (containing $2.5 \mathrm{mM}$ spermidine) was added to the protoplasts and was incubated for $5 \mathrm{~min}$ on ice. Then $200 \mu \mathrm{l}$ of $25 \%$ PEG 3350 (Sigma) in $50 \mathrm{mM}$ $\mathrm{CaCl}_{2}, 10 \mathrm{mM}$ Tris- $\mathrm{HCl}(\mathrm{pH} 7.5)$ was added gently and the mixture was kept on ice for $20 \mathrm{~min}$. After that, $400 \mu \mathrm{l}$ of the same PEG solution was added, mixed gently, and incubated for $20 \mathrm{~min}$ at room temperature. Finally, the transformation mixture was transferred to $100 \mathrm{ml}$ of $\mathrm{SH}$ agar (around $50^{\circ} \mathrm{C}$ ), was mixed gently, and was poured into 10 petri dishes. After $20 \mathrm{~h}$ of incubation at $22^{\circ} \mathrm{C}$, the regenerating protoplasts were overlaid with $5 \mathrm{ml}$ of SH agar containing $50 \mu \mathrm{g}$ of hygromycin B per milliliter. After incubating for 3 to 5 days at $22^{\circ} \mathrm{C}$, the emerging colonies were transferred to MEA plates containing $70 \mu \mathrm{g}$ of hygromycin B per milliliter for further selection. The transformants were verified via PCR with primer pair SJ-F and SJ-R. A 2.4-kb fragment was amplified by PCR from the transformants deriving from homologous integration. The positive transformants were further purified by single-spore isolation to obtain homokaryotic transformed strains. The purified transformants were analyzed by Southern blotting to exclude the transformants with ectopic integration sites.

\section{DNA isolation and Southern blot analysis.}

B. cinerea genomic DNA used for PCR was isolated according to the method described by Cenis (1992). Genomic DNA used for Southern blot was extracted as described by Möller and associates (1992). The molecular probe used for DNA hybridization was amplified and labeled by PCR to incorporate digoxigenin-dUTP (Roche Applied Science, Indianapolis, IN, U.S.A.) into DNA fragment L with primers BSL-F and BSL$\mathrm{R}$. Hybridization was carried out in solution containing $6 \times$ SSPE $\left(1 \times\right.$ SSPE is $0.18 \mathrm{M} \mathrm{NaCl}, 10 \mathrm{mM} \mathrm{NaPO}_{4}$, and $2 \mathrm{mM}$ EDTA [pH 7.7]), $5 \times$ Denhardt's solution $(1 \times$ Denhardt's solution is $0.02 \%$ Ficoll $400,0.02 \%$ polyvinylpyrrolidone, $0.02 \%$ bovine serum albumin), $0.5 \% \mathrm{SDS}$, and $100 \mu \mathrm{g}$ of denatured salmon sperm DNA per milliliter, at $65^{\circ} \mathrm{C}$. Digoxigenin-labeled probe was detected by enzyme immunoassay and enzymecatalyzed color reaction with NBT/BCIP (Roche Applied Science).

\section{Detection of genes expression.}

A suspension containing $10^{6}$ conidia of $B$. cinerea was inoculated in $20 \mathrm{ml}$ of PDB and was incubated at $22^{\circ} \mathrm{C}$ and 160 rpm (HZQ-F100) for $8 \mathrm{~h} . \mathrm{H}_{2} \mathrm{O}_{2}$ was then added into the medium to the final concentrations of 0,5 , and $10 \mathrm{mM}$. After incubating for $1 \mathrm{~h}$, the germinating conidia were collected for RNA extraction. RNA was extracted from frozen germinating conidia ground in liquid nitrogen by Trizol reagent (Tiangen, Beijing). Samples containing $1 \mu \mathrm{g}$ of RNA were treated with 1 U DNase I (Takara, Tokyo) for $30 \mathrm{~min}$, and first-strand cDNA was synthesized using M-MLV reverse transcriptase (Promega, Madison, WI, U.S.A.).
Quantitative real-time PCR was carried out using Step One plus real-time PCR system (AB Applied Biosystems, Foster City, CA, U.S.A.) using SYBR green PCR master mix. Primer pairs were designed by Primer Express software 3.0 (AB Applied Biosystems). The PCR conditions were as follows: $95^{\circ} \mathrm{C}$ for $10 \mathrm{~min}$, followed by 40 cycles of $95^{\circ} \mathrm{C}$ for $15 \mathrm{~s}$, and $60^{\circ} \mathrm{C}$ for $30 \mathrm{~s}$. The change in fluorescence of SYBR green in every cycle was monitored by the system software, and the threshold cycle $\left(C_{t}\right)$ over the background was calculated for each reaction. Samples were normalized using Bcactin and Bctubulin genes, and the relative expression levels were measured using the $2^{(-\Delta \mathrm{Ct})}$ analysis method.

\section{Infection assays.}

The virulence of mutants was assayed on tomato fruits, apple fruits, and tomato leaves. Conidia of wild-type B05.10 and mutants were collected from 2-week-old cultures grown on PDA plates and suspended in a solution containing $10 \mathrm{mM}$ $\mathrm{KH}_{2} \mathrm{PO}_{4}$ and $10 \mathrm{mM}$ glucose at a final concentration of $5 \times 10^{4}$ conidia per milliliter. Prewounded tomato and apple fruits were inoculated with a droplet $(10 \mu \mathrm{l})$ of conidia suspension and were incubated in enclosed plastic trays to maintain a high relative humidity $(95 \%)$ at $25^{\circ} \mathrm{C}$. The detached tomato leaves (4-week-old) were slightly wounded with a hairbrush and were inoculated with $5 \mu \mathrm{l}$ of conidia suspension. The leaves were then incubated in petri dishes at $25^{\circ} \mathrm{C}$. Disease symptoms were scored every day.

\section{Complementation of mutant.}

With primer pair SC-F and SC-R, a 3,070-bp fragment was amplified by PCR, using Phusion high-fidelity DNA polymerase (New England Biolabs, Beverly, MA, U.S.A.). This fragment, including the full length of the Bcsas1 gene, 1,788 bp of the upstream sequence, and 292 bp of the downstream sequence. It was sequenced to ensure flawlessness. This fragment was then cloned into the KpnI-BamHI sites of pCA-sur vector (provided by Z. Ma, Zhejiang University, China), which contains a sur gene, conferring resistance to chlorimuron-ethyl, leading to a plasmid $\mathrm{p} \Delta \mathrm{BS}-\mathrm{C}$ to transform mutant strain. Transformation of mutants with the plasmid $\mathrm{p} \Delta \mathrm{BS}-\mathrm{C}$ was conducted as described above, except that chlorimuron-ethyl $\left(50 \mu \mathrm{g} \mathrm{ml}^{-1}\right)$ was used as selection agent.

\section{Fluorescence microscopy.}

The tip of 3-day-old hypha was cut out from PDA plates and was carefully placed on microscope slides. Droplets $(20 \mu \mathrm{l})$ of $5 \mu$ M FM4-64 (Invitrogen, Carlsbad, CA, U.S.A.) solution was dropped onto the hyphal tips and left for $10 \mathrm{~s}$ at room temperature. The hypha was then observed under fluorescence confocal microscope (LSM 510 META; Carl Zeiss, Oberkochen, Germany). The excitation was at $488 \mathrm{~nm}$ and emitted light was collected at $514 \mathrm{~nm}$.

In order to compare cell wall differences, 3-day-old hyphae were stained with $100 \mu \mathrm{g}$ Calcofluor white per milliliter and were observed under a Nikon Eclipse 800 epifluorescence microscope.

\section{Preparation and relative abundance assay of extracellular proteins.}

A suspension of $5 \times 10^{6}$ conidia was inoculated into $100 \mathrm{ml}$ Czapeck liquid medium. After culturing for $72 \mathrm{~h}$, the filtrated supernatant was centrifuged at $20,000 \times g$ at $4^{\circ} \mathrm{C}$ for $1 \mathrm{~h}$ to remove impurities, $0.03 \%$ (wt/vol) DOC (sodium deoxycholate) was then added to the supernatant, followed by careful mixing and incubation on ice for $30 \mathrm{~min}$. Subsequently, the extracellular proteins were precipitated for $30 \mathrm{~min}$ on ice with ice-cold trichloric acetic acid at the final concentration of $10 \%$ 
(wt/vol). The proteins were collected by centrifugation at $16,000 \times g$ at $4^{\circ} \mathrm{C}$ for $30 \mathrm{~min}$ and were washed three times with cold acetone. After air drying, the protein pellets were solubilized in $200 \mu \mathrm{l}$ of lysis buffer ( $2 \mathrm{M}$ thiourea, $7 \mathrm{M}$ urea, $4 \%$ [wt/vol] CHAPS, $1 \%$ [wt/vol] dithiothreitol, and 2\% [vol/ vol] carrier ampholytes). For the relative abundance assay, the mycelium was separated from the supernatant and was dried to determine mass. The amount of supernatant used for protein extraction was adjusted, based on the dry mass obtained from the cultures. The protein samples were separated on $12 \%$ (wt/ vol) SDS-PAGE gel and were silver stained.

\section{Determination of extracellular polygalacturonase and xylanase activities.}

Extracellular mediums cultured for $72 \mathrm{~h}$ were used for polygalacturonase and xylanase activity assays. For the polygalacturonase activity assay, pectin was used as substrate and the activity was expressed as the production of D-galacturonic acid per hour and per microgram of protein (Jiang et al. 2010). For the xylanase activity assay, xylan was used as substrate and the activity was expressed as the production of xylose per hour and per microgram of protein (Jeffries et al. 1998).

\section{2-D gel electrophoresis and image analysis.}

For 2-D gel electrophoresis, 250- $\mu$ g aliquots of extracellular protein extracted from 5-day-old culture and resolved in 250 $\mu \mathrm{l}$ of lysis buffer were used to rehydrate gel strips (Immobiline Dry Strip, pH 4 to 7, $13 \mathrm{~cm}$; GE Healthcare, Piscataway, NJ, U.S.A.) for $16 \mathrm{~h}$. The 2-D electrophoresis and gel staining were carried out according to the method described by $\mathrm{Li}$ and associates (2010).

The stained gels were scanned using a flatbed scanner (Amersham Biosciences, Uppsala, Sweden) and were saved in TIF format. Image analysis was performed by Image Master 2D Elite software (Amersham Biosciences). Three biological replicate gels resulting from three independent experiments were analyzed for $B$. cinerea wild type and $\Delta B$ csas 1 mutant. The amount of a protein spot was calculated based on the volume of that spot, and the spot volume was normalized as a percentage of the total volume of all spots. The normalized intensity of spots on three replicate 2-D gels was averaged, and a two-tailed nonpaired Student's $t$-test was used to determine whether the relative change was statistically significant between samples, using SPSS software (SPSS, Inc., Chicago). Protein spots whose secretion levels changed significantly were excised for protein identification.

\section{In-gel digestion, MS, and database searching.}

In-gel digestion was performed as described by Qin and associates (2011). Protein spots were excised from the 2-D gels and were destained with $50 \mathrm{mM} \mathrm{NH} \mathrm{HCO}_{3}$ in $50 \%$ (vol/vol) methanol for $1 \mathrm{~h}$ at $40^{\circ} \mathrm{C}$. After completely drying in a vacuum centrifuge, the gel pieces were digested at $37^{\circ} \mathrm{C}$ for $16 \mathrm{~h}$ with $10 \mathrm{ng}$ of trypsin per microliter. Digested peptides were extracted by three changes of $0.1 \%$ trifluoroacetic acid (TFA) in $50 \%$ acetonitrile, were lyophilized, and were submitted to matrixassisted laser desorption-ionization time of flight (MALDITOF)/TOF MS/MS.

For MALDI-TOF/TOF MS/MS analysis, peptides were resuspended with $10 \mu \mathrm{l}$ of $70 \%$ acetonitrile containing $0.1 \%$ TFA, and $1 \mu \mathrm{l}$ was taken and spotted onto the AnchorChip MALDI target plate (Bruker Daltonics, Billerica, MA, U.S.A.). Then, 1 $\mu \mathrm{l}$ of matrix solution (1 mg ml $\mathrm{m}^{-1}$, a-cyano-4-hydroxycinnamic acid in $70 \%$ acetonitrile containing $0.1 \%$ TFA) was spotted after the sample solution dried. Mass spectra were acquired on a MALDI-TOF/TOF mass spectrometer (UltrafleXtreme; Bruker Daltonics). The instrument was operated in the positive reflection mode and was externally calibrated using the peptide calibration kit (Bruker Daltonics). MS spectra were acquired with 400 laser shots per spectrum, whereas MS/MS spectra were obtained using 1,500 laser shots per fragmentation spectrum. To acquire the MS/MS fragmentation spectra, the 15 strongest peaks of each MS spectra were selected as precursor ions, which excluded trypsin autolytic peptides and other known background ions.

For database searching, MS data were uploaded with Biotools software (ver. 3.2; Bruker Daltonics) to Mascot for database searching on the Matrix Science public web site and were searched against NCBInr protein databases (version 20120107; $16,831,682$ sequences and 5,781,564,572 residues). Search parameters were set as fungi; proteolytic enzyme, trypsin; max missed cleavages, 1; fix modifications, carbamidomethyl (C); variable modifications, oxidation $(\mathrm{M})$; peptide mass tolerance, $100 \mathrm{ppm}$; fragment mass tolerance, $0.5 \mathrm{Da}$. Only significant hits as defined by Mascot probability analysis were considered.

\section{ACKNOWLEDGMENTS}

We thank P. Tudzynski (Westfaelische Wilhelms-Universitaet Muenster, Germany) and J. van Kan (Wageningen Agricultural University, The Netherlands) for kindly supporting B. cinerea haploid strain B05.10 and plasmid pLOB7, respectively. We also thank M. Wisniewski (Appalachian Fruit Research Station USDA-ARS U.S.A.) for critically reading this manuscript. The work was supported by the 973 program (grant number 2013CB127103), by National Natural Science Foundation of China (grant number 31030051) and by the Chinese Academy of Sciences (grant number KSCX2-EW-G-6). The funders had no role in study design, data collection and analysis, decision to publish, or preparation of the manuscript.

\section{LITERATURE CITED}

Brito, N., Espino, J. J., and Gonzalez, C. 2006. The endo- $\beta-1,4$-xylanase Xyn11A is required for virulence in Botrytis cinerea. Mol. PlantMicrobe Interact. 19:25-32.

Cenis, J. L. 1992. Rapid extraction of fungal DNA for PCR amplification. Nucleic Acids Res. 20:2380.

Chanda, A., Roze, L. V., Kang, S., Artymovich, K. A., Hicks, G. R., Raikhel, N. V., Calvo, A. M., and Linz, J. E. 2009. A key role for vesicles in fungal secondary metabolism. Proc. Natl. Acad. Sci. U.S.A. 106:19533-19538.

Chen, S., Liang, M. C., Chia, J. N., Ngsee, J. K., and Ting, A. E. 2001. Rab8b and its interacting partner TRIP8b are involved in regulated secretion in AtT20 cells. J. Biol. Chem. 276:13209-13216.

Clément, M., Fournier, H., de Repentigny, L., and Belhumeur, P. 1998. Isolation and characterization of the Candida albicans SEC4 gene. Yeast 14:675-680.

Conesa, A., Punt, P. J., van Luijk, N., and van den Hondel, C. A. M. J. J. 2001. The secretion pathway in filamentous fungi: A biotechnological view. Fung. Genet. Biol. 33:155-171.

Dumas, B., Borel, C., Herbert, C., Maury, J., Jacquet, C., Balsse, R., and Esquerré-Tugayé, M. T. 2001. Molecular characterization of CLPT1, a SEC4-like Rab/GTPase of the phytopathogenic fungus Colletotrichum lindemuthianum which is regulated by the carbon source. Gene 272:219-225.

English, P. D., and Albersheim, P. 1969. Host-pathogen interactions: I. A Correlation between $\alpha$-galactosidase production and virulence. Plant Physiol. 44:217-224.

Espino, J. J., Gutiérrez-Sánchez, G., Brito, N., Shah, P., Orlando, R., and González, C. 2010. The Botrytis cinerea early secretome. Proteomics 10:3020-3034.

Esquerré-Tugayé, M. T., Boudart, G., and Dumas, B. 2000. Cell wall degrading enzymes, inhibitory proteins and oligosaccharides participate in the molecular dialogue between plant and pathogens. Plant Physiol. Biochem. 38:157-163.

Fischer-Parton, S., Parton, R. M., Hickey, P. C., Dijksterhuis, J., Atkinson, H. A., and Read, N. D. 2000. Confocal microscopy of FM4-64 as a tool for analyzing endocytosis and vesicle trafficking in living fungal hyphae. J. Microsc. 198:246-259.

Frías, M., González, C., and Brito, N. 2011. BcSpl1, a cerato-platanin family protein, contributes to Botrytis cinerea virulence and elicits the hypersensitive response in the host. New Phytol. 192:483-495.

Goud, B., Salminen, A., Walworth, N. C., and Novick, P. J. 1988. A GTP- 
binding protein required for secretion rapidly associates with secretory vesicles and the plasma membrane in yeast. Cell 53:753-768.

Grosshans, B. L., Ortiz, D., and Novick, P. 2006. Rabs and their effectors: Achieving specificity in membrane traffic. Proc. Natl. Acad. Sci. U.S.A. 103:11821-11827.

Hamada, W., Reignault, P., Bompeix, G., and Boccara, M. 1994. Transformation of Botrytis cinerea with the hygromycin B resistance gene, $h p h$. Curr. Genet. 26:251-255.

Hattula K., Furuhjelm J., Tikkanen J., Tanhuanpaa K., Laakkonen P., and Peranen J. 2006. Characterization of the Rab8-specific membrane traffic route linked to protrusion formation. J. Cell. Sci. 119:4866-4877.

Huber, L. A., Pimplikar, S., Parton, R. G., Virta, H., Zerial, M., and Simons, K. 1993. Rab8, a small GTPase involved in vesicular traffic between the TGN and the basolateral plasma membrane. J. Cell. Biol. 123:35-45.

Jamet, E., Canut, H., Boudart, G., and Pont-Lezica, R. F. 2006. Cell wall proteins: A new insight throuth proteomics. Trends Plant Sci. 11:33-39.

Jeffries, T. W., Yan, V. W., and Davis, M. W. 1998. Comparative study of xylanase kinetics using dinitrosalicylic, arsenomolybdate and ion chromatographic assays. Appl. Biochem. Biotechnol. 70-72:257-265.

Jiang, N. N., Rao, J. P., Fu, R. S., and Suo, J. T. 2010. Effects of propylene and 1-Methylcyclopropene on PG activities and expression of DkPG1 gene during Persimmon softening process. Acta Hortic. Sinica. 37:1507-1512.

Kim, K. S., Min, J.-Y., and Dickman, M. B. 2008. Oxalic acid is an elicitor of plant programmed cell death during Sclerotinia sclerotiorum disease development. Mol. Plant-Microbe Interact. 21:605-612.

Li, B. Q., Wang, W. H., Zong, Y. Y., Qin, G. Z., and Tian, S. P. 2012. Exploring pathogenic mechanisms of Botrytis cinerea secretome under different ambient $\mathrm{pH}$ based on comparative proteomic analysis. J. Proteome Res. 11:4249-4260.

Mao, Y., Kalb, V. F., and Wong, B. 1999. Overexpression of a dominant negative allele of SEC4 inhibits growth and protein secretion in Candida albicans. J. Bacteriol. 181:7235-7242.

Möller, E. M., Bahnweg, G., Sandermann, H., and Geiger, H. H. 1992. A simple and efficient protocol for isolation of high molecular weight DNA from filamentous fungi, fruit bodies and infected plant tissues. Nucleic Acids Res. 20:6115-6116.

Naglik, J. R., Challacombe, S. J., and Hube, B. 2003. Candida albicans secreted aspartyl proteinases in virulence and pathogenesis. Microbiol. Mol. Biol. Rev. 67:400-428.

Nielsen, E., Cheung, A. Y., and Ueda, T. 2008. The Regulatory RAB and ARF GTPases for Vesicular Trafficking. Plant Physiol. 147:1516-1526.

Noda, J., Brito, N., and Gonzalez, C. 2010. The Botrytis cinerea xylanase Xyn11A contributes to virulence with its necrotizing activity, not with its catalytic activity. BMC Plant Biol. 10:38.

Novick, P., and Zerial, M. 1997. The diversity of Rab proteins in vesicle transport. Curr. Opin. Cell Biol. 9:496-504.

Peranen J., Auvinen P., Virta H., Wepf R., and Simons K. 1996. Rab8 promotes polarized membrane transport through reorganization of actin and microtubules in fibroblasts. J. Cell Biol. 135:153-167.

Pereira-Leal, J. B. 2008. The Ypt/Rab family and the evolution of trafficking in fungi. Traffic 9:27-38.

Pereira-Leal, J. B., and Seabra, M. C. 2000. The mammalian Rab family of small GTPases: Definition of family and subfamily sequence motifs suggests a mechanism for functional specificity in the Ras superfamily. J. Mol. Biol. 301:1077-1087.

Pereira-Leal, J. B., and Seabra, M. C. 2001. Evolution of the Rab family of small GTP binding proteins. J. Mol. Biol. 313:889-901.

Punt, P. J., Seiboth, B., Weenink, X. O., van Zeijl, C., Lenders, M., Konetschny, C., Ram, A. F. J., Montijn, R., Kubicek, C. P., and van den Hondel, C. A. M. J. J. 2001. Identification and characterization of a family of secretion-related small GTPase-encoding genes from the filamentous fungus Aspergillus niger: A putative SEC4 homologue is not essential for growth. Mol. Microbiol. 41:513-525.

Qin, G. Z., Liu, J., Cao, B. H., Li, B. Q., and Tian, S. P. 2011. Hydrogen peroxide acts on sensitive mitochondrial proteins to induce death of a fungal pathogen revealed by proteomic analysis. PLoS ONE 7:e21945. Published online

Reichard, U., Cole, G. T., Hill, T. W., Ruchel, R., and Monod, M. 2000. Molecular characterization and influence on fungal development of ALP2, a novel serine proteinase from Aspergillus fumigatus. Int. J. Med. Microbiol. 290:549-558.
Rutherford, S., and Moore, I. 2002. The Arabidopsis Rab GTPase family: Another enigma variation. Curr. Opin. Plant Biol. 5:518-528.

Sakaguchi, M. 1997. Eukaryotic protein secretion. Curr Opin Biotechnol. 8:595-601.

Salminen, A., and Novick, P. J. 1987. A ras-like protein is required for a post-Golgi event in yeast secretion. Cell 49:527-538.

Sato, T., Mushiake, S., Kato, Y., Sato, K., Sato, M., Takeda, N., Ozono, K., Miki, K., Kubo, Y., Tsuji, A., Harada, R., and Harada, A. 2007. The Rab8 GTPase regulates apical protein localization in intestinal cells. Nature 448:366-369.

Schouten, A., van Baarlen, P., van Kan, J. A. L. 2008. Phytotoxic Nep1like proteins from the necrotrophic fungus Botrytis cinerea associate with membranes and the nucleus of plant cells. New Phytol. 177:493505.

Segal, A. W. 2005. How neutrophils kill microbes. Annu. Rev. Immunol. 23:197-223.

Siriputthaiwan, P., Jauneau, A., Herbert, C., Garcin, D., and Dumas, B. 2005. Functional analysis of CLPT1, a Rab/GTPase required for protein secretion and pathogenesis in the plant fungal pathogen Colletotrichum lindemuthianum. J. Cell Sci. 118:323-329.

Stenmark, H., and Olkkonen, V. M. 2001. The Rab GTPase family. Genome Biol. 2:3007.1-3007.7.

Stubbs, H. J., Brasch, D. J., Emerson, G. W., and Sullivan, P. A. 1999. Hydrolase and transferase activities of the $\beta$-1,3-exoglucanase of Candida albicans. Eur. J. Biochem. 263:889-895.

Tamano, K., Satoh, Y., Ishii, T., Terabayashi, Y., Ohtaki, S., Sano, M., Takahashi, T., Koyama, Y., Mizutani, O., Abe, K., and Machida, M. 2007. The $\beta$-1,3-Exoglucanase gene exgA (exg1) of Aspergillus oryzae is required to catabolize extracellular glucan, and is induced in growth on a solid surface. Biosci. Biotechnol. Biochem. 71:926-934.

Temme, N., and Tudzynski, P. 2009. Does Botrytis cinerea ignore $\mathrm{H}_{2} \mathrm{O}_{2}$ induced oxidative stress during infection? Characterization of Botrytis activator protein 1. Mol. Plant-Microbe Interact. 22:987-998.

ten Have, A., Espino, J. J., Dekkers, E., van Sluyter, S.C., Brito, N., Kay, J., González, C., and van Kan, J. A. L. 2010. The Botrytis cinerea aspartic proteinase family. Fungal Genet. Biol. 47:53-65.

ten Have, A., Mulder, W., Visser, J., and van Kan, J. A. L. 1998. The endopoly-galacturonase gene Bcpgl is required for full virulence of Botrytis cinerea. Mol. Plant-Microbe Interact. 11:1009-1016.

Valette-Collet, O., Cimerman, A., Reignault, P., Levis, C., and Boccara, M. 2003. Disruption of Botrytis cinerea pectin methylesterase gene Bcpme1 reduces virulence on several host plants. Mol. Plant-Microbe Interact. 16:360-367.

Van den Hazel, H. B., Kielland-Brandt, M. C., and Winther, J. R. 1996. Review: Biosynthesis and function of yeast vacuolar proteases. Yeast $12: 1-16$.

Vida, T. A., and Emr, S. D. 1995. A new vital stain for visualizing vacuolar membrane dynamics and endocytosis in yeast. J. Cell Biol. 128:779792.

Vu, B. V., Itoh, K., Nguyen, Q. B., Tosa, Y., and Nakayashiki, H. 2012. Cellulases belonging to glycoside hydrolase families 6 and 7 contribute to the virulence of Magnaporthe oryzae. Mol. Plant-Microbe Interact. 25:1135-1141.

Walworth, N. C., Goud, B., Kabcenell, A. K., and Novick, P. J. 1989. Mutational analysis of SEC4 suggests a cyclical mechanism for the regulation of vesicular traffic. EMBO (Eur. Mol. Biol. Organ.) J. 8:16851693.

Williamson, B., Tudzynski, B., Tudzynski, P., and van Kan, J. A. L. 2007. Botrytis cinerea: The cause of grey mould disease. Mol. Plant Pathol. 8:561-580.

Yajima, W., Liang, Y., and Kav, N. N. V. 2009. Gene disruption of an arabinofuranosidase/ $\beta$-xylosidase precursor secreases Sclerotinia sclerotiorum virulence on canola tissue. Mol. Plant-Microbe Interact. 22:783-789.

\section{AUTHOR-RECOMMENDED INTERNET RESOURCES}

Broad Institute Botrytis cinerea genome database: www.broad.mit.edu/annotation/genome/botrytis_cinerea

Matrix Science web site: www.matrixscience.com

Pathogen-Host Interactions database: www.phibase.org 